
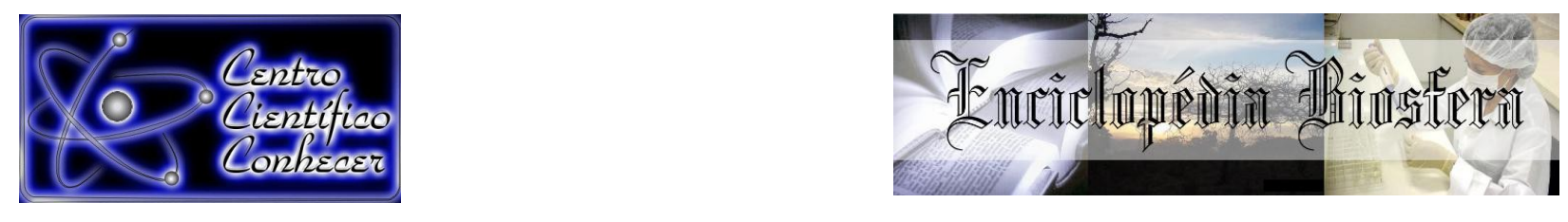

\title{
ADUBAÇÃO BIOLÓGICA E COM BIOESTIMULANTE NO DESENVOLVIMENTO DO MILHO
}

Elston Kraft ${ }^{1}$, Carolina Riviera Duarte Maluche Baretta ${ }^{2}$, André Junior Ogliari ${ }^{3}$, Patrícia Nogueira ${ }^{4}$, Leandro do Prado Wildner ${ }^{5}$

${ }^{1}$ Mestrando do Programa de Pós-Graduação em Ciência do Solo da Universidade do Estado de Santa Catarina (elston@unochapeco.edu.br) - Lages, SC - Brasil ${ }^{2}$ Professora Doutora da Universidade Comunitária da Região de Chapecó - Chapecó , SC - Brasil

${ }^{3}$ Mestrando do Programa de Pós-Graduação em Ciências Ambientais da

Universidade Comunitária da Região de Chapecó - Chapecó, SC - Brasil

${ }^{4}$ Mestranda do Programa de Pós-Graduação em Agronomia da Universidade de Passo Fundo - Passo Fundo, RS - Brasil

${ }^{5}$ Pesquisador do Centro de Pesquisa para Agricultura Familiar (CEPAF) da Empresa de Pesquisa Agropecuária e Extensão Rural de Santa Catarina - Chapecó, SC Brasil

Recebido em: 06/04/2018 - Aprovado em: 10/06/2018 - Publicado em: 20/06/2018 DOI: 10.18677/EnciBio_2018A2

\begin{abstract}
RESUMO
O aumento da utilização de produtos biotecnológicos na agricultura amplia a necessidade da realização de estudos que mensurem sua real eficiência. $O$ estudo objetivou avaliar parâmetros vegetativos e de rendimento do milho submetido à adubação biológica e com um bioestimulante. O experimento foi conduzido em casa de vegetação utilizando vasos plásticos, no delineamento inteiramente casualizado com seis repetições, em Latossolo Vermelho distrófico. Os tratamentos corresponderam às doses comerciais dos fertilizantes testados: AB1 e AB2 - adubo composto de microrganismos benéficos nas doses 200 e $500 \mathrm{~g} \mathrm{ha}^{-1}$, respectivamente; $\mathrm{BIO}$ - bioestimulante na dose de $200 \mathrm{~mL} \mathrm{ha}^{-1}$; AB1 (200 $\left.\mathrm{g} \mathrm{ha}^{-1}\right)+$ BIO (200 mL ha-1) - combinação de fertilizantes; e o tratamento controle. Avaliou-se a estatura de planta, diâmetro de colmo, comprimento de raiz, massa seca de raiz, massa seca de parte aérea, e massa seca de 100 grãos. Os fertilizantes promoveram em estádio vegetativo maior crescimento radicular e promoção do aumento do rendimento medido através da massa seca de 100 grãos. Conclui-se para o presente experimento que a utilização de ambos os produtos apresentam-se como alternativa para o aumento da produtividade do milho, necessitando ampliar tais estudos para as condições de campo.
\end{abstract}

PALAVRAS-CHAVE: estádios fenológicos, sustentabilidade, Zea mays L 


\begin{abstract}
The increase in the use of biotechnological products in agriculture increases the need to carry out studies that measure their real efficiency. The objective of this study was to evaluate vegetative and yield parameters of maize submitted to biological fertilization and with a biostimulant. The experiment was conducted in a greenhouse using plastic pots, in the completely randomized design with six replicates, in Dystrophic Red Latosol. The treatments corresponded to the commercial doses of the tested fertilizers: $A B 1$ and $A B 2$ - fertilizer composed of beneficial microrganisms at doses 200 and $500 \mathrm{~g} \mathrm{ha}^{-1}$, respectively; $\mathrm{BIO}$ biostimulant at the dose of $200 \mathrm{~mL} \mathrm{ha}^{-1}$; AB1 $\left(200 \mathrm{~g} \mathrm{ha}^{-1}\right)+\mathrm{BIO}(200 \mathrm{~mL} \mathrm{ha-1})-$ combination of fertilizers; and control treatment. Plant height, stalk diameter, root length, root dry mass, shoot dry mass, and dry matter of 100 grains were evaluated; Fertilizers promoted a higher root growth and increased the yield measured by the dry mass of 100 grains. It is concluded for the present experiment that the use of both products are presented as an alternative for the increase of maize productivity, needing to extend such studies to the field conditions.
\end{abstract}

KEYWORDS: phenological stages, sustainability, Zea mays L

\title{
INTRODUÇÃO
}

O milho (Zea mays L.) é uma cultura mundialmente importante em virtude de sua diversidade de utilização, da extensão da área cultivada e da elevada capacidade produtiva. De acordo com a Companhia Nacional de Abastecimento (CONAB, 2017), o Brasil é o terceiro maior produtor e o segundo maior exportador do cereal a nível mundial, alcançando aproximadamente 351 milhões de toneladas produzidas na safra 2016/2017, com uma média de produção superior a $5,5 \mathrm{t} \mathrm{ha}^{-1}$. Muitos destes resultados se devem aos avanços das cultivares, condições climáticas, fertilidade e ao aporte de produtos biotecnológicos.

As abordagens biotecnológicas para melhorar a produção ganham destaque na busca por um sistema integrado de manejo sustentável da produção agrícola. Meios de produção mais sustentáveis incluem práticas de manejo que favoreçam a manutenção da qualidade dos solos e a reposição de nutrientes essenciais às plantas. Microrganismos benéficos como rizobactérias promotoras de crescimento de plantas, podem auxiliar na diminuição do uso de fertilizantes químicos, preservando os recursos hídricos e o solo e, por consequência, promover o aumento da produção com redução de custos do manejo (AHEMAD; KIBRET, 2014; MONTEIRO et al., 2014; OLIVEIRA et al., 2015).

É possível encontrar adubos biológicos constituintes de compostos orgânicos de origem animal ou vegetal que podem ser aplicados ao solo, junto a sementes ou via adubação foliar; contendo na sua composição nutrientes, proteínas, enzimas, fenóis, hormônios do crescimento, entre outros compostos (PENTEADO, 2004; MEDEIROS; LOPES, 2006). Além de fornecerem nutrientes e matéria orgânica, alguns desses fertilizantes promovem o aumento da biodiversidade e atividade biológica com benefícios para o solo e planta (ALBIACHI et al., 2000). A presença de bactérias promotoras de crescimento de plantas em alguns destes fertilizantes estimulam as plantas por meio da mobilização, transformação e solubilização de nutrientes no solo, produzindo inúmeros reguladores de crescimento, protegendo-as de fitopatógenos, melhorando a estrutura do solo e promovendo a biorremediação de solos contaminados (HAYAT et al., 2010; AHEMAD; KIBRET, 2014), demonstrando a relevância na manutenção e melhoria da qualidade dos solos, bem 
como no que diz respeito ao crescimento e desenvolvimento das culturas (DORAN; PARKIN, 1994; TODA et al., 2010).

Assim, a utilização de biorreguladores, inoculantes, fertilizantes biológicos ou bioestimulantes surgem como alternativas na estratégia de manejo das lavouras (MARTINS et al., 2016). Os bioestimulantes atuam diretamente nas diferentes estruturas celulares, propiciando alterações físicas, químicas e metabólicas, processos vitais e estruturais da planta (BINSFELD et al., 2014). Além disto, a utilização destes promove o equilíbrio hormonal e nutricional das plantas, favorecendo a expressão do potencial genético (CARVALHO et al., 2013).

Até o presente momento, poucos estudos mensuram o efeito da adubação biológica e utilização de bioestimulante combinados ou de maneira isolada, para a cultura do milho. Desta maneira, no intuito de gerar informações sobre o assunto, o presente trabalho objetivou avaliar parâmetros vegetativos e de rendimento do milho submetido à adubação biológica e com bioestimulante.

\section{MATERIAL E MÉTODOS}

O experimento foi realizado em casa de vegetação localizada na área experimental da Empresa de Pesquisa Agropecuária e Extensão Rural de Santa Catarina (EPAGRI/CEPAF/CHAPECÓ), no Município de Chapecó - SC, no período de janeiro a maio de 2015.

O delineamento experimental utilizado foi inteiramente casualizado, com seis repetições. Os tratamentos corresponderam à utilização de dois fertilizantes orgânicos: um fertilizante orgânico $100 \%$ natural (Adubação biológica - BacSol $^{\circledR}$ ) e um bioestimulante - fertilizante orgânico composto complexado de aminoácidos $\left(\right.$ OrgaSol $^{\circledR}$ ), e a combinação de ambos, aplicados nas sementes no período que antecedeu à semeadura, conforme recomendação dos fabricantes. O Bacsol ${ }^{\circledR}$ é um composto que contém uma gama de microrganismos como bactérias do gênero Bacillus, Pseudomonas, Nitrosomonas e Nitrobacter (MONTEIRO et al., 2014), além de fungos como Saccharomyces cerevisiae (SPANIOL et al., 2014). Conforme Monteiro e Auer (2012), o produto é um formulado constituído, na maioria, por células bacterianas. O Orgasol $^{\circledR}$, por sua vez, consiste de um complexo organomineral à base de aminoácidos essenciais, considerado bioestimulante precursor de hormônios e enzimas, e apresenta na composição micronutrientes essenciais tais como boro $(B)$, manganês $(M n)$, molibdênio (Mo) e zinco $(Z n)$, além do macronutriente enxofre (S) (RSA INDÚSTRIA DE INSUMOS AGRÍCOLA LTDA, 2014).

Os tratamentos corresponderam às doses recomendadas pelo fabricante: AB1 e AB2 - adubo composto de microrganismos benéficos nas doses de 200 e 500 $\mathrm{g} \mathrm{ha}^{-1}$ do produto comercial, respectivamente $(0,16 \mathrm{~g} / \mathrm{vaso}$ e $0,40 \mathrm{~g} / \mathrm{vaso})$; $\mathrm{BIO}$ bioestimulante na dose de $200 \mathrm{~mL} \mathrm{ha}^{-1}$ do produto comercial $(0,16 \mathrm{~mL} / \mathrm{vaso}) ; A B 1$ $\left(200 \mathrm{~g} \mathrm{ha}^{-1}\right)+$ BIO (200 mL ha-1) - combinação de fertilizantes; e o tratamento controle que não recebeu os fertilizantes, totalizando cinco tratamentos com seis repetições, dispostos em 30 vasos plásticos com $18 \mathrm{dm}^{-3}$ de solo.

O solo utilizado para o experimento foi um Latossolo Vermelho distrófico (EMBRAPA, 2013) coletado na camada 0,00 - 0,20 m de profundidade no município de Chapecó - SC, onde inicialmente foi tamisado com malha de $4 \mathrm{~mm}$ de abertura e incubado com calcário dolomítico de PRNT 75\% por um período de 60 dias. Durante o experimento, a umidade do solo foi corrigida e mantida em torno de $60 \%$ da capacidade de campo por meio de regas diárias. 
Utilizou-se na condução do experimento o híbrido de milho comercial 2B610PW (Dow AgroScience). Todos os tratamentos receberam adubação mineral com base na necessidade da cultura obtida pela recomendação da Comissão de Química e Fertilidade do Solo RS/SC (CQFS - RS/SC, 2004), a partir da análise do solo: $580 \mathrm{~g} \mathrm{~kg}^{-1}$ de argila; $\mathrm{pH}$ em $\mathrm{H}_{2} \mathrm{O}$ de 4,9; $2,9 \mathrm{cmolc} \mathrm{dm}^{-3}$ de Al; $5,1 \mathrm{mg} \mathrm{dm}^{-3}$ de P; $57,6 \mathrm{mg} \mathrm{dm}^{-3}$ de K; 0,2 $\mathrm{cmolc} \mathrm{dm}^{-3}$ de Ca; $0,3 \mathrm{cmolc} \mathrm{dm}^{-3}$ de $\mathrm{Mg}$ e conteúdo de matéria orgânica de $29 \mathrm{~g} \mathrm{~kg}^{-1}$.

Para a adubação de base foi aplicado $0,39 \mathrm{~g}$ vaso $^{-1}$ de $\mathrm{N} ; 1,41 \mathrm{~g}$ vaso-1 de $\mathrm{P}_{2} \mathrm{O}_{5}$; e $0,51 \mathrm{~g}$ vaso-1 de $\mathrm{K}_{2} \mathrm{O}$; correspondente a $30 \mathrm{~kg} \mathrm{ha}^{-1}$ de N; $145 \mathrm{~kg} \mathrm{ha}^{-1}$ de $\mathrm{P}_{2} \mathrm{O}_{5}$; e $60 \mathrm{~kg} \mathrm{ha}^{-1}$ de $\mathrm{K}_{2} \mathrm{O}$. A adubação de cobertura foi realizada no estádio V6 utilizando $1,93 \mathrm{~g}$ vaso de $\mathrm{Ne} 0,63 \mathrm{~g}$ vaso de $\mathrm{K}_{2} \mathrm{O}$, correspondente a $90 \mathrm{~kg} \mathrm{ha}^{-1}$ de $\mathrm{N}$ e $40 \mathrm{~kg} \mathrm{ha}^{-}$ ${ }^{1}$ de $\mathrm{K}_{2} \mathrm{O}$, para uma expectativa de rendimento de $8 \mathrm{t} \mathrm{ha}^{-1}$.

A semeadura do milho foi realizada no dia 09 de janeiro de 2015, utilizando cinco sementes por vaso em profundidade de $5 \mathrm{~cm}$. O primeiro desbaste ocorreu cinco dias após a emergência (DAE) deixando duas plantas por vaso, e aos 11 DAE foi realizado o segundo desbaste deixando apenas uma planta por vaso. Durante o período do experimento foram realizados os tratamentos fitossanitários conforme as necessidades, por meio da observação e acompanhamento permanente da cultura.

Foram realizadas avaliações no estádio vegetativo (V6) e de maturidade fisiológica (R6) do milho. Para a avaliação em estádio vegetativo (V6) foram avaliadas as variáveis: estatura de planta (EP) medindo-se a distância vertical entre a superfície do solo e o ponto de inserção da última folha completamente expandida, utilizando-se régua graduada em $\mathrm{cm}$; o diâmetro de colmo (DC) medido com a utilização de um paquímetro digital; massa seca da parte aérea (MSPA) com as plantas cortadas rente ao solo, colocadas em sacos de papel, identificados e transferidos para estufa a $65{ }^{\circ} \mathrm{C}$ até obtenção de massa constante; massa seca de raiz (MSR) com as raízes lavadas, secas a sombra por 24 horas e posteriormente colocadas em sacos de papel, identificados e transferidos para estufa a $65{ }^{\circ} \mathrm{C}$ até obtenção de massa constante; e comprimento de raiz (CR) utilizando-se de régua graduada em $\mathrm{cm}$.

Em estádio reprodutivo (R6), foram determinadas as variáveis acima citadas, com exceção das variáveis MSR e CR (devido ao grande desenvolvimento radicular, dificultando a recuperação da mesma na massa de solo e mensuração correta da mesma), sendo também acrescida a avaliação do componente de rendimento através da variável massa de 100 grãos (MSG) com umidade corrigida a 13\%.

As avaliações de EP e DC realizadas em V6 foram realizadas nas seis repetições (vasos) dos tratamentos enquanto, para as avaliações de MSPA, MSR e CR foram sorteados e retirados três vasos por tratamento. As avaliações realizadas em estádio R6 foram realizadas em três repetições (vasos) por tratamento. Os dados obtidos foram submetidos à análise de variância (ANOVA), utilizando-se o programa estatístico SAS, versão 6.12 (SAS, 1990), e as médias comparadas pelo teste LSD $(P<0,05)$.

\section{RESULTADOS E DISCUSSÃO}

\section{Avaliação em estádio vegetativo da cultura (V6)}


Enquanto, a variável diâmetro de colmo (DC) não apresentou diferença estatística significativa, as variáveis analisadas: estatura de planta (EP), comprimento de raiz (CR), massa seca de raiz (MSR) e massa seca de parte aérea (MSPA) diferiram estatisticamente entre os tratamentos testados (Tabela 1).

Domingues Neto et al. (2013) avaliando a aplicação foliar de cinco concentrações de bactérias promotoras de crescimento na cultura do milho, não obtiveram diferença estatística para a variável diâmetro de colmo aos 49 dias após a emergência. Os autores atribuem o resultado à baixa influência dos produtos testados em estádios iniciais de desenvolvimento da cultura, corroborando aos dados obtidos neste experimento.

Para a EP constatou-se apenas diferença estatística do tratamento que não recebeu os fertilizantes em relação ao tratamento com adubação biológica na maior dose (AB2) que apresentou a menor EP; com os demais tratamentos não diferindo entre si (Tabela 1). Tais dados evidenciam que os fertilizantes testados não promovem ganhos quanto à estatura de planta. A inibição ao crescimento de parte aérea $(E P)$ do tratamento $A B 2$ em relação ao controle está associada a maior concentração do adubo biológico podendo gerar condições de maior dreno de carbono e fotoassimilados pelos organismos, restringindo o crescimento da parte aérea, uma vez que a associação entre microrganismos e a planta hospedeira gera um dreno a mesma, sendo muitas vezes está condição temporária (MOREIRA; SIQUEIRA, 2006).

TABELA 1 - Parâmetros vegetativos do milho (Zea mays L.) avaliados em estádio V6 da cultura, na utilização de adubação biológica e com bioestimulante: diâmetro de colmo (DC), estatura de planta (EP), comprimento de raiz (CR), massa seca de raiz (MSR) e massa seca de parte aérea (MSPA).

\begin{tabular}{|c|c|c|c|c|c|}
\hline Tratamentos & DC & EP & CR & MSR & MSPA \\
\hline & \multicolumn{3}{|c|}{ 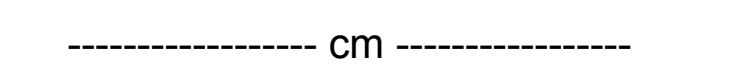 } & \multicolumn{2}{|c|}{------- g ------- } \\
\hline Controle $^{1}$ & $1,55^{\mathrm{ns}}$ & $20,95 a^{*}$ & $53,66 c^{* *}$ & $2,92 a^{* *}$ & $5,48 a^{* *}$ \\
\hline AB1 & 1,47 & $19,72 a b$ & $107,06 \mathrm{ab}$ & $2,88 \mathrm{a}$ & $3,42 b$ \\
\hline AB2 & 1,28 & $18,25 b$ & $101,58 \mathrm{~b}$ & $3,42 \mathrm{a}$ & $2,81 \mathrm{~b}$ \\
\hline $\mathrm{BIO}$ & 1,34 & $20,60 a b$ & 118,45 a & $1,97 \mathrm{~b}$ & $2,90 \mathrm{~b}$ \\
\hline $\mathrm{AB} 1+\mathrm{BIO}$ & 1,36 & $20,58 \mathrm{ab}$ & $111,65 \mathrm{ab}$ & $3,31 \mathrm{a}$ & $4,82 \mathrm{a}$ \\
\hline CV \% & 15,64 & 9,20 & 4,33 & 10,32 & 10,33 \\
\hline
\end{tabular}

${ }^{1}$ Controle sem utilização dos fertilizante testados; $A B 1$ e $A B 2$ - adubo composto de microrganismos benéficos nas doses de 200 e $500 \mathrm{~g} \mathrm{ha}^{-1}$, respectivamente; BIO - bioestimulante a $200 \mathrm{~mL} \mathrm{ha}^{-1}$; AB1 $\left(200 \mathrm{~g} \mathrm{ha}^{-1}\right)+\mathrm{BIO}\left(200 \mathrm{~mL} \mathrm{ha}^{-1}\right)$ - combinação de fertilizantes. Médias seguidas pela mesma letra em cada coluna não diferem estatisticamente pelo teste de Tukey. ${ }^{* *}$ e ns: significância a $P<0,01$ e não significativo, respectivamente.

Para o CR o maior valor obtido foi no tratamento com a utilização do bioestimulante $(\mathrm{BIO})$, que diferiu estatisticamente dos tratamentos com adubação biológica na maior dose ( $A B 2)$ e, sem a utilização dos fertilizantes (controle), não diferindo dos demais tratamentos ( $A B 1$ e $A B 1+B I O)$ (Tabela 1). $O$ menor $C R$ foi encontrado para o tratamento controle, representando aproximadamente $50 \%$ de redução de comprimento em relação aos demais tratamentos (Tabela 1). Dessa forma, o melhor desenvolvimento radicular aumenta a área de exploração do solo 
favorecendo o desenvolvimento da cultura, principalmente em épocas de estresse hídrico, além de aumentar a atividade biológica do solo em camadas mais profundas por meio da liberação de mucilagens e lisados - compostos prontamente utilizáveis pela comunidade microbiana (VINHAL-FREITAS; RODRIGUES, 2010; CORDEIRO et al., 2012).

Pesquisas mostram o papel dos microrganismos como estimulantes ao crescimento vegetal ao provocarem alterações que estimulam a formação de pelos radiculares e raízes secundárias, resultando em maior superfície de absorção de água e nutrientes (RADWAN et al., 2004). Binsfeld et al. (2014) encontraram resultados positivos utilizando produtos contendo auxinas para esta mesma variável no crescimento inicial, quando testado na cultura da soja.

A auxina é o hormônio vegetal responsável pelo alongamento das células (TAIZ; ZEIGER, 2009), podendo sua produção ser estimulada pela atividade microbiana de bactérias promotoras do crescimento de plantas, como aquelas presentes no produto utilizado como adubação biológica (tratamentos $A B 1$ e $A B 2$ ) (AHEMAD; KIBRET, 2014), e pelo próprio bioestimulante (tratamento BIO) capaz de ativar fisiologicamente todo o processo vital da planta atuando em nível de enraizamento.

Embora o tratamento $\mathrm{BIO}$ tenha proporcionado maior $\mathrm{CR}$, este comprimento não refletiu em maior massa seca de raiz (MSR), apresentando os menores valores para esta variável, diferindo dos demais tratamentos estudados que não diferiram entre si (Tabela 1). Os maiores valores encontrados para o CR no tratamento com utilização somente de bioestimulante (BIO) está condicionado ao maior desenvolvimento de raízes laterais que contribuem para a elongação das raízes, porém, não proporcionando o aumento do diâmetro destas (SILVA et al., 2014), o que não refletiu no aumento da massa seca, como observado no presente estudo, mas contribui para o aumento de área de absorção de água e nutrientes (TAIZ; ZEIGER, 2009).

Para MSR e MSPA em avaliação vegetativa, o uso dos produtos de forma individual ou combinada não se apresentaram eficientes, promovendo ora diminuição destes parâmetros quando comparado ao controle, ora não diferindo dos valores encontrados para o tratamento que não recebeu os tratamentos (Tabela 1). Contrariamente ao presente estudo, Santos et al. (2013) avaliando o uso de bioestimulante, bactérias promotoras de crescimento e a associação de ambos constataram que o uso de bioestimulante individualmente apresentou a melhor resposta para massa seca de folha e massa seca de colmo, sendo que a testemunha apresentou a pior resposta aos 45 dias após a emergência (DAE). Conceição et al. (2008), avaliando o uso de ácido húmico e bactérias promotoras de crescimento em milho, não encontraram diferença estatística para a MSPA no desenvolvimento inicial da cultura.

Os dados obtidos na avaliação em estádio vegetativo sugerem que a utilização dos produtos nos estádios iniciais de desenvolvimento do milho, seja de forma individual ou conjunta, demonstrou eficiente para aumentar a área de exploração do solo pelo crescimento radicular (CR), o que pode refletir em maior adaptação da planta em condições de estresse hídrico e aumento na absorção de nutrientes (VINHAL-FREITAS; RODRIGUES, 2010; CORDEIRO et al., 2012), refletindo no rendimento (Tabela 2 ).

\section{Avaliação em estádio reprodutivo da cultura (R6)}


Enquanto, a variável EP não apresentou diferença estatística significativa (Tabela 2), as variáveis analisadas DC, MSPA e massa seca de 100 grãos (MSG) diferiram estatisticamente entre os tratamentos testados. A variável EP não diferiu estatisticamente entre os tratamentos, no entanto para as variáveis DC e MSPA nenhum tratamento testado apresentou-se superior aos valores encontrados para o tratamento controle, apesar de haver diferença estatística. Não houve benefício da utilização dos fertilizantes testados de maneira isolada ou associados, em relação a estes parâmetros analisados. Em alguns tratamentos a utilização dos mesmos apresentou efeito negativo para estes parâmetros avaliados quando comparado ao controle (Tabela 2).

TABELA 2 - Parâmetros vegetativos e de rendimento do milho (Zea mays L.) avaliados em estádio R6 da cultura na utilização de adubação biológica e bioestimulante: diâmetro de colmo (DC), estatura de planta (EP), massa seca de parte aérea (MSPA), e massa seca de 100 grãos (MSG).

\begin{tabular}{|c|c|c|c|c|}
\hline Tratamentos & EP & DC & MSPA & MSG \\
\hline & \multicolumn{2}{|c|}{--- cm --- } & \multicolumn{2}{|c|}{$---g$--- } \\
\hline Controle $^{1}$ & $216,66^{\text {ns }}$ & $1,86 a b^{* *}$ & $75,85 a^{* *}$ & $16,89 b^{* *}$ \\
\hline AB1 & 228,00 & $1.75 \mathrm{bc}$ & $67,32 \mathrm{~cd}$ & 21,23 a \\
\hline AB2 & 226,83 & $1,60 \mathrm{c}$ & $69,84 \mathrm{bc}$ & 20,23 a \\
\hline $\mathrm{BIO}$ & 210,66 & $2,00 \mathrm{a}$ & $74,09 \mathrm{ab}$ & $20,75 a$ \\
\hline $\mathrm{AB} 1+\mathrm{BIO}$ & 218,00 & $1,69 \mathrm{bc}$ & $64,13 \mathrm{~d}$ & $20,05 \mathrm{a}$ \\
\hline CV \% & 4,13 & 4,98 & 2,36 & 2,69 \\
\hline
\end{tabular}

${ }^{1}$ Controle sem utilização dos fertilizante testados; $A B 1$ e $A B 2$ - adubo composto de microrganismos benéficos nas doses de 200 e $500 \mathrm{~g} \mathrm{ha}^{-1}$, respectivamente; BIO - bioestimulante a $200 \mathrm{~mL} \mathrm{ha}^{-1}$; AB1 $\left(200 \mathrm{~g} \mathrm{ha}^{-1}\right)+\mathrm{BIO}\left(200 \mathrm{~mL} \mathrm{ha}{ }^{-1}\right)$ - combinação de fertilizantes. Médias seguidas pela mesma letra em cada coluna não diferem estatisticamente pelo teste de Tukey. ${ }^{* *}$ e ns: significância a $P<0,01$ e não significativo, respectivamente.

Parâmetros como DC e MSPA têm apresentado na literatura diferentes resultados quanto à utilização de adubos biológicos e bioestimulantes. Semelhantemente aos resultados encontrados neste estudo Krenchinski et al. (2014), não encontraram diferença estatística para a utilização de bioestimulantes quando comparados a testemunha, sobre o diâmetro de colmo no milho de segunda safra. Enquanto, resultados obtidos por Domingues Neto et al. (2013), na mesma época de avaliação do presente estudo, demonstraram que a aplicação via foliar de $3 \mathrm{~mL} \mathrm{~L}^{-1}$ de bactérias promotoras de crescimento mostrou-se superior à testemunha na cultura do milho para MSPA.

Em estudo conduzido por Bento et al. (2016) em condições de campo na cultura do milho, utilizando os produtos Orgasol $^{\circledR}$ e Bacsol $^{\circledR}$ de maneira conjunta aplicados ao sulco de semeadura e com diferentes níveis de fósforo, obtiveram respostas significativas dos produtos para a variável massa seca de planta, salientando que os melhores resultados foram obtidos nas menores doses de fósforo aplicados. No entanto não se obteve diferença quanto ao diâmetro de colmo e estatura da planta.

Segundo Sangoi et al. (2011), Farinelli et al. (2012), maiores diâmetros de colmo conferem a planta maior resistência ao acamamento, bem como maior capacidade para o suporte de folhas e espiga, além de ser um órgão de reserva que acumula sacarose, e que pode ser translocada para as espigas na fase de 
enchimento de grãos quando a fonte de produção de fotoassimilados não suprir as necessidades da planta.

Dados encontrados por Cunha et al. (2016), avaliando bioestimulante, bactérias diazotróficas e biorregulador na cultura do milho, demonstraram efeito positivo do bioestimulante em relação à testemunha, e negativo para utilização de bactérias, corroborando parcialmente com os dados obtidos nesta pesquisa.

$\mathrm{Na}$ literatura são reconhecidas as associações simbióticas ou mutualísticas entre plantas e microrganismos, os quais são capazes de conferir tolerância a doenças, ajuste osmótico, controle na abertura e fechamento de estômatos, alterações morfológicas das raízes e alterar a produção e distribuição de hormônios (ESPOSITO-POLESI, 2011), sendo estes reguladores dos processos fisiológicos das plantas, incluindo crescimento e reprodução (KONG et al., 2012), podendo desta maneira afetar de forma positiva ou negativa nos processos de crescimento e desenvolvimento da planta.

A MSG apresentou diferença estatística a $1 \%$ de significância, sendo que todos os tratamentos testados foram superiores ao tratamento controle; no entanto, os mesmos não diferiram entre si (Tabela 3). Os tratamentos testados obtiveram em média uma produção superior em aproximadamente $19 \%$ em relação ao tratamento controle, demonstrando a eficiência da utilização de microrganismos e bioestimulante. Resultados estes que contestam os encontrados por Oliveira et al. (2015) e Krenchinski et al. (2014). Segundo Domingues Neto et al. (2013), o genótipo da planta é o fator-chave para que se obtenha sucesso na associação entre microrganismos e o uso de bioestimulantes com as mesmas.

Os dados obtidos por Bento et al. (2016), para a massa de 1000 grãos, em condição de campo, diferiram estatisticamente apenas na dose de $20 \mathrm{Kg} \mathrm{ha}^{-1}$ de fósforo com e sem os inoculantes, e apesar não haver diferença estatística nas demais doses, cabe salientar que com a utilização dos produtos os resultados foram superiores do que quando os mesmos não foram utilizados.

O fertilizante testado no presente estudo $\left(\right.$ Bacsol $^{\circledR}$ ) apresenta em sua composição microrganismos classificados como rizosféricos, nitrificantes, decompositores e de controle biológico sendo desenvolvido com a finalidade de aumentar a produção de grãos (MONTEIRO et al., 2014). As bactérias contidas no produto utilizado como adubação biológica são percursoras de vários fitohormônios reguladores de crescimento de plantas, desenvolvendo funções importantes tais como produção de auxinas, etileno e amônia, solubilização de fosfatos, atividade antifúngica e solubilizadora de metais pesados (HAHN et al., 2013; AHEMAD; KIBRET, 2014; OLIVEIRA et al., 2015). Estes organismos crescem na rizosfera da planta estimulando o crescimento e desenvolvimento das mesmas por multiplicidade de mecanismos, funcionando como uma extensão do sistema radicular (SANTOS et al., 2015).

Desta maneira, os resultados obtidos para o rendimento de planta podem ser advindos por um conjunto de fatores, sejam pela solubilização e disponibilização de nutrientes, alterações hormonais, mudança no conjunto da população microbiológica do solo ou diminuindo o efeito de condições adversas. Os fertilizantes demonstraram potencial de utilização para a cultura, contudo, os autores não excluem a necessidade de outros estudos em condições de campo para repetibilidade dos resultados obtidos em casa de vegetação, bem como o efeito em outras culturas de interesse comercial.

\section{CONCLUSÃO}


Os fertilizantes testados demonstraram efeito positivo quanto ao crescimento da raiz do milho nos estádios iniciais de desenvolvimento da cultura; enquanto, não houve efeito da utilização dos mesmos quando comparados ao tratamento controle para os demais parâmetros vegetativos estudados. Em estádio reprodutivo, todos os tratamentos promoveram o aumento da massa seca de 100 grãos em relação ao tratamento controle.

\section{AGRADECIMENTOS}

Os autores agradecem à Empresa de Pesquisa Agropecuária e Extensão Rural de Santa Catarina (EPAGRI/CEPAF/CHAPECÓ) por ceder o espaço físico para realização da pesquisa.

\section{REFERÊNCIAS}

AHEMAD, M.; KIBRET, M. Mechanisms and applications of plant growth promoting rhizobacteria: current perspective. Journal of King Saud University - Science, v. 26, p. 1-20, 2014. Disponível em: <https://doi.org/10.1016/j.jksus.2013.05.001>. doi: 10.1016/j.jksus.2013.05.001

ALBIACH, R.; CANET, R.; POMARES, F.; INGELMO, F. Microbial biomass content and enzymatic activities after the application of organic amendments to a horticultural soil. Bioresource Technology, v. 75, n. 1, p. 43-48, 2000. Disponível em: <https://doi.org/10.1016/S0960-8524(00)00030-4>. doi: 10.1016/S09608524(00)00030-4

BENTO, R. U.; PELÁ, A.; RIBEIRO, M. de A.; SILVA, J. A. G.; CRUZ, S. J. S. Contribuição de bioestimulantes contendo microrganismos rizosféricos na absorção de fósforo pelo milho. Revista Brasileira de Milho e Sorgo, v. 15, n. 3, p. 572-581, 2016. Disponível em:<http://dx.doi.org/10.18512/1980-6477/rbms.v15n3p573-582>. doi: 10.18512/1980-6477/rbms.v15n3p573-582

BINSFELD, J. A.; BARBIERI, A. P. P.; HUTH, C.; CABRERA, I. C.; HENNING, L. M. M. Uso de bioativador, bioestimulante e complexo de nutrientes em sementes de soja. Pesquisa Agropecuária Tropical, v. 44, n. 1, p. 88-94, jan./mar. 2014. Disponível em: <http://www.scielo.br/pdf/pat/v44n1/v44n1a10.pdf>. Acesso em: 28 dez. 2017.

CARVALHO, T. C. de; SILVA, S. S. da; SILVA, R. C. da.; PANOBIANCO, M.; MÓRGON, A. F. Influência de bioestimulantes na germinação e desenvolvimento de plântulas de Phaseolus vulgaris sob restrição hídrica. Revista de Ciências Agrárias, v. 36, n. 2, p. 199-205, 2013. Disponível em: <http://www.scielo.mec.pt/scielo.php?script=sci_arttext\&pid=S0871-

018X2013000200009\&lng=pt\&nrm=iso>. Acesso em: 28 out. 2017.

CONAB - Companhia Nacional de Abastecimento. Acompanhamento da Safra Brasileira. Grãos. Nov/2017. Disponível em: <http://www.conab.gov.br/OlalaCMS/uploads/arquivos/17_12_01_09_55_21_boletim _de_grao_-_2o_lev_2017.pdf>. Acesso em: 15 dez. $201 \overline{7}$.

CONCEIÇÃO, P. M.; VIEIRA, H. D.; CANELLAS, L. P.; JUNIOR, R. B. M.; OLIVARES, F. L. Recobrimento de sementes de milho com ácidos húmicos e 
bactérias diazotróficas endofíticas. Pesquisa Agropecuária Brasileira, v. 43, n. 4, p. 545-548, 2008. Disponível em: <http://www.scielo.br/scielo.php? script=sci_arttext\&pid=S0100-204X2008000400015\&Ing=en\&nrm=iso>. . doi: $10.1590 / \bar{S} 0100-204 X 2008000400015$

CQFS-RS/SC - Comissão de química e fertilidade do solo - RS/SC. Manual de adubação e calagem para os Estados do Rio Grande do Sul e de Santa Catarina. 10 ed. Porto Alegre: SBCS - Núcleo Regional Sul/UFRGS, 2004. 400p

CORDEIRO, M. A. S.; CORÁ, J. E.; NAHAS, E. Atributos bioquímicos e químicos do solo rizosférico e não rizosférico de culturas em rotação no sistema de semeadura direta. Revista Brasileira de Ciência do Solo, v. 36, p. 1794-1803, 2012. Disponível em: $\quad$ http://www.scielo.br/scielo.php?script=sci_arttext\&pid=S010006832012000600013\&Ing=en\&nrm=iso>. doi: 10.1590/S0100-06832012000600013

CUNHA, R. G. da.; LIMA, S. F. da; ALVAREZ, R. de C. F.; SIMON, C. A.; CONTARDI, L. M. Arranjo espacial e biorreguladores de crescimento na produtividade de milho. Revista de Ciências Agroambientais, v. 14, n. 2, p. 22-31, 2016. <https://periodicos.unemat.br/index.php/rcaa/article/view/1263/1527>. Acesso em: 10 jul. 2017.

DOMINGUES NETO, F. J.; YOSHIMI, F. K.; GARCIA, R. D.; MIYAMOTO, Y. R.; DOMINGUES, M. C. S. Desenvolvimento e produtividade do milho verde safrinha em resposta à aplicação foliar com Azospirillum brasiliense. Enciclopédia Biosfera, v. 9, n. 17, p. 1030-1040, 2013. Disponível em: <http://www.conhecer.org.br/enciclop/2013b/CIENCIAS

$\% 20$ AGRARIAS/desenvolvimento\%20e\%20produtividade.pdf>. Acesso em: 20 out. 2017.

DORAN, J. W.; PARKIN, T. B. Defining and assessing soil quality. In: DORAN, J. W.; COLEMAN, D. C.; BEZDICEK, D. F.; STEWART, B. A. Defining soil quality for a sustainable environment. Madison: SSSA, 1994. p. 3-21.

EMBRAPA. Centro Nacional de Pesquisa de Solos. Sistema Brasileiro de Classificação de solos. 3 ed. Brasília: Embrapa produção de informação; Rio de Janeiro: Embrapa Solos, 2013. 353p.

ESPOSITO-POLESI, N. P. Microrganismos endofíticos e a cultura de tecidos vegetais: quebrando paradigmas. Revista Brasileira de Biociência, v. 9, n. 4, p. 533-541, out./dez. 2011. Disponível em: <http://www.ufrgs.br/seerbio/ojs/index.php/rbb/article/view/1914>. Acesso em: 07 jul. 2017.

FARINELLI, R.; PENARIOL, F.G.; FORNASIERI FILHO, D. Características agronômicas e produtividade de cultivares de milho em diferentes espaçamentos entrelinhas e densidades populacionais. Científica, v. 40, n. 1, p. 21-27, 2012. Disponível em: <http://cientifica.org.br/index.php/cientifica/article/view/325>. Acesso em: 17 set. 2017. 
HAHN, L.; SÁ, E. L. S. de; SILVA, W. R. da; MACHADO, R. G.; DAMASCO, R. G. Promoção de crescimento de híbridos de milho inoculados com rizóbios e bactérias diazotróficas associativas. Pesquisa Agropecuária Gaúcha, v. 19, n. 1/2, p. 46-56, 2013. Disponível em: <http://www.fepagro.rs.gov.br/upload/1434657443_04.pdf>. Acesso em: 15 out. 2017.

HAYAT, R.; ALI, S.; AMARA, U.; KHALID, R.; AHMED, I. Soil beneficial bacteria and their role in plant growth promotion: a review. Annals of Microbiology, v. 60, p. 579-598, 2010. Disponível em: <https://link.springer.com/article/10.1007/s13213010-0117-1>. Acesso em: 05 ago. 2017.

KONG, L.; ADERKAS, P. V.; OWEN, S. J.; JAQUISH, B.; WOODS, J. et al. Effects of stem girdling on cone yield and endogenous phytohormones and metabolites in developing long shoots of Douglas-fir (Pseudotsuga menziesii). New Forest, v. 43, p. 491-503, 2012. Disponível em: <http://dx.doi.org/ 10.1007/s11056-011-9294-4>. doi: $10.1007 / \mathrm{s} 11056-011-9294-4$

KRENCHINSKI, F. H.; ALBRECHT, L. P.; KRENCHINSKI, L. R.; PLACIDO, H. F.; ALBRECHT, A. J. P. et al. Utilização de bioestimulante organomineral no milho de segunda safra cultivado no Oeste do Paraná. Revista Agrarian, v. 7, p. 468-473, 2014. Disponível em: <http://ojs.ufgd.edu.br/index.php/agrarian/article/view/1966>. Acesso em: 19 out. 2017.

MARTINS, D. C.; BORGES, I. D.; CRUZ, J. C.; MARTINS NETTO, D. C. Produtividade de duas cultivares de milho submetidas Ao tratamento de sementes com bioestimulantes, fertilizantes líquidos e Azospirillum sp. Revista Brasileira de Milho e Sorgo, v. 15, n. 2, p. 217-228, 2016. Disponível em: <http://dx.doi.org/10.18512/1980-6477/rbms.v15n2p217-228>. doi: 10.18512/19806477

MEDEIROS, M. B.; LOPES, J. S. Biofertilizantes líquidos e sustentabilidade agrícola. Revista Bahia Agrícola, v. 8, n. 3, p. 24-26, 2006. Disponível em: $<$ http://www.seagri.ba.gov.br/sites/default/files/comunicacao05_v7n3.pdf>. Acesso em: 22 out. 2017.

MONTEIRO, P. H. R.; WINAGRASKI, E.; AUER, C. G. Importância do uso de rizobactérias na produção de mudas florestais. Colombo, PR, Embrapa Floresta, 2014. 6p. (Comunicado técnico, 338). Disponível em: <https://www.embrapa.br/busca-de-publicacoes/-/publicacao/1010557/importanciado-uso-de-rizobacterias-na-producao-de-mudas-florestais>. Acesso em: 10 mai. 2017.

MONTEIRO, P. R.; AUER, C. G. Avaliação do crescimento de mudas de Eucalyptus benthamii após uso do Bacsol. In: FERTBIO 2012, "A Responsabilidade Socioambiental da Pesquisa Agrícola". Viçosa, MG: Sociedade Brasileira de Ciência do Solo- SBCS, 2012.

MOREIRA, F. M. S.; SIQUEIRA, J. O. Microbiologia e bioquímica do solo. 2 ed. atualizada e ampliada - Lavras, MG: Editora UFLA, 2006, 729p. 
OLIVEIRA, M. A.; ZUCARELI, C.; FERREIRA, A. S.; DOMINGUES, A. R.; SPOLAOR, L. T.; NEVES, C. S. V. J. Adubação fosfatada associada à inoculação com Pseudomonas fluorescens no desempenho agronómico do milho. Revista de Ciências Agrárias, v. 38, n. 1, p. 18-25, 2015. Disponível em: <http://www.scielo.mec.pt/scielo.php?script=sci_arttext\&pid=S0871-

018X2015000100004\&lng=pt\&nrm=iso>. Acesso em: 28 out. 2017.

PENTEADO, S. R. Adubação orgânica, preparo de compostos e biofertilizantes. Campinas-SP: Vida Orgânica, 2004, 89p.

RADWAN, T. E. E.; MOHAMED, Z. K.; REIS, V. M. Efeito da inoculação de Azospirillum e Herbaspirillum na produção de compostos indólicos em plântulas de milho e arroz. Pesquisa Agropecuária Brasileira, v. 39, n. 10, p. 987-994, out. 2004. Disponível em: <http://www.scielo.br/scielo.php?script=sci_arttext\&pid=S0100204X2004001000006\&Ing=en\&nrm=iso>. doi: 10.1590/S0100-204 X2004001000006

RSA Indústria de Insumos Agrícolas LTDA. São Paulo, SP: Bacsol, 2014. Bula.

SANGOI, L.; SCHEWEITZER, C.; SILVA, P. R. F. da.; SCHIMITT, A.; VARGAS, V. $P$. et al. Perfilhamento, área foliar e produtividade do milho sob diferentes arranjos espaciais. Pesquisa Agropecuária Brasileira, Brasília, v. 46, n. 6, p. 609-616, jun. 2011. <https://www.alice.cnptia.embrapa.br/bitstream/doc/901647/1/46n06a06.pdf>. doi: 10.1590/S0100-204X2011000600006

SANTOS, V. M.; MELO, A. V.; CARDOSO, D. P.; GONÇALVES, A. H.; VARANDA, M. A. F. et al. Uso de bioestimulantes no crescimento de plantas de Zea mays $L$. Revista Brasileira de Milho e Sorgo, v. 12, n. 3, p. 307-318, 2013. Disponível em: <http://dx.doi.org/1018512/1980-6477/rbms.v12n3p307-318>. doi: 1018512/19806477/rbms.v12n3p307-318

SANTOS, J. da S.; VIANA, T. de O.; JESUS, C. M. de.; BALDANI, L. D.; FERREIRA, J. S. Inoculation and isolation of plant growth-promoting bacteria in maize grown in Vitória da Conquista, Bahia, Brazil. Revista Brasileira de Ciência do Solo, v. 39, n. 1, p. 78-85, 2015. Disponível em: <http://www.scielo.br/scielo.php? script=sci_arttext\&pid=S0100-06832015000100078\&lng=en\&nrm=iso >. $10.1590 / 01000683 \mathrm{rbcs} 20150725$

SAS INSTITUTE. SAS: User's guide: estatistics. 6th ed. Cary: Institute Inc. 2002.

SILVA, I. F.; ARAUJO NETO, S. E.; KUSDRA, J. F. Biological activity of soils under systems of organic farming, agroforestry and pasture in the Amazon. Revista Ciência Agronômica, v. 45, n. 3, p. 427-432, jul-set, 2014. Disponível em: <http://www.scielo.br/scielo.php?script=sci_arttext\&pid=S1806-

66902014000300001\&lng=en\&nrm=iso>. doi: 10.1590/S1806-66902014000300001

SPANIOL, J. S.; OLTRAMARI, C. E.; LOCATELLI, M.; VOLPATO, A.; CAMPIGOTTO, G. et al. Influence of probiotic on somatic cell count in milk and immune system of dairy cows. Comparative Clinical Pathology, v. 24, n. 3, p. 677- 
681, 2014. Disponível em: <https://doi.org/10.1007/s00580-014-1966-y>. doi: 10.1007/s00580-014-1966-y

TAIZ, L.; ZEIGER, E. Fisiologia vegetal. 4. ed. Porto Alegre: Artmed, 2009. 820p.

TODA, F. E.; VAQUES, T.; ARAÚJO, F. F. Biomassa microbiana e sua correlação com a fertilidade de solos em diferentes sistemas de cultivo. Colloquium Agrariae, v. 6 , n. 2, p. 01-07, 2010. doi: 10.5747/ca.2010.v06.n2.a051

VINHAL-FREITAS, A.C; RODRIGUES, M. B. Fixação biológica do nitrogênio na cultura do milho. Agropecuária Técnica, v. 31, n. 2, p. 143-154, 2010. Disponível em: <http://periodicos.ufpb.br/ojs2/index.php/at/article/view/4515/4636>. doi: 10.25066/agrotec.v31i2.4515 